\title{
Central Venous Access Devices Revisited in a Resource Poor Context
}

\author{
Dr.Jyosthna Elagandula ${ }^{1}$, Dr.Pradeep Kumar Reddy K ${ }^{1}$, Prakash G. Chitalkar ${ }^{2}$ \\ ${ }^{1}$ Senior resident, Department of Medical Oncology, Sri Aurobindo Institute Of Medical Sciences \\ ${ }^{2}$ Professor and Head, Department of Medical Oncology, Sri Aurobindo Institute Of Medical Sciences \\ DOI: 10.29322/IJSRP.11.06.2021.p11460 \\ http://dx.doi.org/10.29322/IJSRP.11.06.2021.p11460
}

\begin{abstract}
Introduction: Cancer patients require long-term venous access for frequent administration of chemotherapy, antibiotics, blood components and ocassionally total parenteral nutrition. Introduction of central venous catheters (CVCs) in the 1980s has revolutionized the quality of life of cancer patients. These devices helped with patient compliance and satisfaction by minimizing the need for repeated venipunctures and associated emotional trauma.
\end{abstract}

Aims and Objectives: To review our experience of CVADs over a one year period and analyze the outcome with regard to different types of catheters used, difficulties during insertion, catheter indwelling period, reasons for removal, incidence of infections and mechanical complications in the rural setting.

Material and method: Sixty three CVADs placed in patients with hematological malignancies and solid tumors from March 2019 to February 2020 at SAIMS hospital were taken into study and were analyzed.

Results: Sixty three CVADs were placed in 58 patients. The median catheter indwelling period was, 94 days (21days - 295 days) for PICC and 137 days (72 days - 356 days) for CP. Nineteen out of 58 patients developed complications (32.7\%). There were 5 episodes of Catheter Related Blood Stream Infection. Eleven (17.4\%) mechanical complications were noted and 3 patients $(4.7 \%)$ had thrombotic complications.

Conclusion: Use of CVAD is a safe, reliable way of administration of chemotherapy and other supportive medication in developing countries. The incidence of complications and catheter loss was acceptable. The cost of the device and its maintenance forms a crucial factor especially in developing countries like India. It requires expert handling care and a specialized nurse.

Index Terms- Central venous catheters, catheter related blood stream infection (CRBSI), chemotherapy, chemoport.

\section{INTRODUCTION}

$\mathrm{T}$ he management of cancer patients requires repeated venous punctures in view of prolonged treatment, frequent blood sampling for clinical monitoring and microbial cultures, administration of chemotherapy, blood products, antibiotics, and other supportive medication. The introduction of central venous catheters (CVCs) in the 1980s has simplified these interventions and improved the quality of life of cancer patients. CVC insertion and care requires a specialized multidisciplinary team of surgeons, oncologists, interventional radiologists, and nurses. However, these devices are associated with problems such as mechanical, thrombotic and infectious complications.

We reviewed the profile of patients with CVCs over one year and analyzed the outcomes: types of catheters used, difficulty during insertion, catheter indwelling period, reasons for removal, the incidence of infections, and mechanical complications at an Oncology Centre in the rural setting.

\section{MATERIALS AND METHODS}

Data of patients admitted at SAIMS hospital and undergoing central venous catheterization for cancer management from March 2019 to February 2020 were analyzed retrospectively. Case files were retrieved for demographic profile, indication of insertion, type of catheter, indwelling catheter period, complications and indications for removal.

\section{RESULTS}

Sixty-three CVCs were inserted in 58 patients. Five patients had more than one CVC placement. Twenty-two (34.9\%) CVC insertions were in pediatric patients and forty-one $(65.1 \%)$ in adults. Forty-five $(71.4 \%)$ were for hematological cancers with Acute Lymphoblastic Leukemia being most common, and eighteen (28.6\%) were for solid malignancies (Figure 1).

Figure 1: Pie chart showing various diagnoses of patients

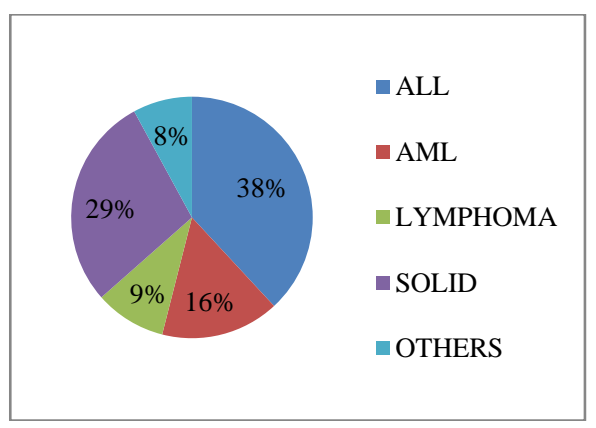

Forty-five $(71.4 \%)$ CVCs were peripherally inserted central catheters (PICC) and eighteen $(28.6 \%)$ were Chemo ports (CP) (figure 2). 
Figure 2: Bar diagram showing demographic data of patients

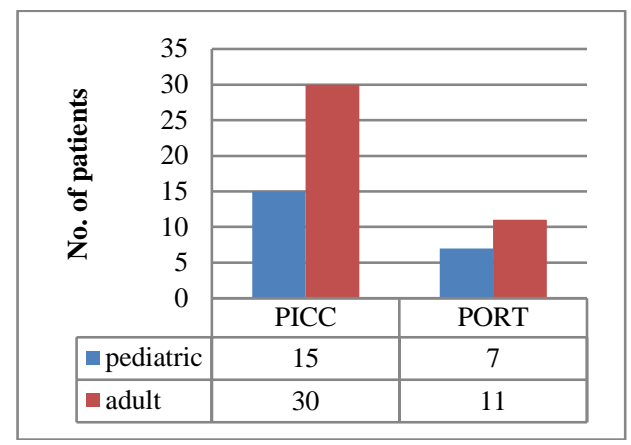

Eighteen PICC were Cavafix and twenty-seven were Bard Groshong. Ultrasonography guidance was used for four PICC insertions. During a one-year follow up, median catheter indwelling period was 94 days $(21-295)$ for PICC and 137 days $(72-356)$ for chemo ports. Nineteen out of $58(32.7 \%)$ patients developed complications.

\section{COMPLICATIONS}

The overall incidence of catheter-related complications was 47.6\%. Eleven (17.4\%) mechanical complications were noted during catheter indwelling period such as catheter lumen occlusion in five, catheter leak in three, and persistent withdrawal occlusion in three. Infectious complications were noted in ten $(15.8 \%)$ of which four were exit site infections, five were Catheter-Related Blood Stream Infection (CRBSI) and one was a pocket infection of chemo port. Of 26 blood cultures for febrile neutropenia, five $(19.2 \%)$ yielded isolates. Staphylococcus aureus was the most common organism. Three patients $(4.7 \%)$ had thrombotic complications. One patient with chemo port had persistent pain and swelling in the upper limb (Table 1).

Table 1: Complications during catheter indwelling period

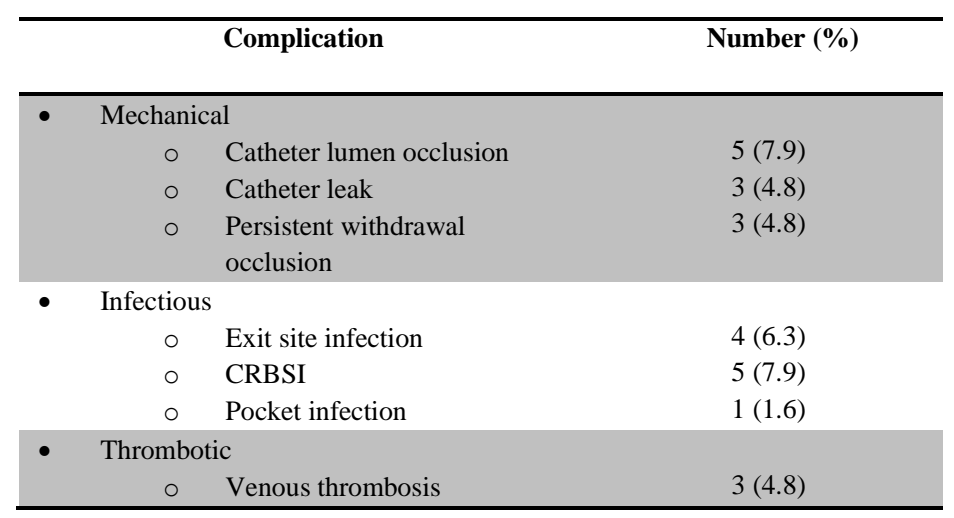

This publication is licensed under Creative Commons Attribution CC BY.

http://dx.doi.org/10.29322/IJSRP.11.06.2021.p11460

\section{REASONS FOR REMOVAL}

At the time of analysis, 19 CVCs were still in use and 44 had been removed. Thirteen $(20.6 \%)$ were removed on completion of treatment. Fifteen $(23.8 \%)$ were removed prematurely due to complications such as catheter lumen blockade in five, deep vein thrombus in three, CRBSI in five, pocket infection in one, and persistent pain with swelling of upper limb in one. Two were removed on account of patient's refusal for chemotherapy. Six catheters $(7.9 \%)$ were lost due to accidental dislodgement (Table 2).

Table 2: Reasons for catheter removal

\begin{tabular}{|c|c|c|c|c|c|}
\hline \multicolumn{3}{|c|}{ PICC } & \multicolumn{3}{|c|}{ CHEMOPORT } \\
\hline & Reason & No. & & Reason & No. \\
\hline 0 & $\begin{array}{l}\text { Treatment } \\
\text { completion }\end{array}$ & 10 & 0 & $\begin{array}{l}\text { Treatment } \\
\text { completion }\end{array}$ & 3 \\
\hline ○ & $\begin{array}{l}\text { Catheter lumen } \\
\text { blockade }\end{array}$ & 5 & $\begin{array}{l}0 \\
0\end{array}$ & $\begin{array}{l}\text { CRBSI } \\
\text { Venous }\end{array}$ & $\begin{array}{l}1 \\
1\end{array}$ \\
\hline o & Accidental & 6 & & thrombosis & \\
\hline 0 & $\begin{array}{l}\text { dislodgement } \\
\text { Venous }\end{array}$ & 2 & o & $\begin{array}{l}\text { Pocket } \\
\text { infection }\end{array}$ & 1 \\
\hline & thrombosis & & ० & Persistent pain & 1 \\
\hline ○ & CRBSI & 4 & & and swelling in & \\
\hline 0 & Patient refusal & 2 & & the arm & \\
\hline
\end{tabular}

\section{DISCUSSION}

The use of CVCs in oncology practice has increased during the past decades. Types of CVCs include tunneled catheters, nontunneled catheters, implantable subcutaneous chemo ports and peripherally inserted central catheters. The choice of the catheter depends on the expected duration of use, chemotherapy regimen, cost involved and patient preference. ${ }^{[1]}$ The cost of the device along implantation charges form a crucial factor especially in resource poor country like India. This was reflected in our study with most of the CVCs being PICC (71.4\%) compared to chemo port $(28.6 \%)$.

Chemoports are effective for long term use in patients with cancer compared to other CVCs. In our study, the median indwelling period was 137 days for CPs and 94 days for PICCs. A study of 180 patients by Babu et al reported similar findings with catheter indwelling period being greatest in patients with $\mathrm{CP}$ (137 days) and least in PICC patients (59days). ${ }^{\text {[2] }}$

The incidence of catheter-related complications in current study was $47.6 \%$ with $17.4 \%$ mechanical and $15.8 \%$ infective cause, comparable to study by Babu et alwith $41.2 \%$ complications, with $22.4 \%$ mechanical and $18.8 \%$ infective. ${ }^{[2]}$ Jain et al had $19 \%$ complications with $12 \%$ mechanical and $7 \%$ infective, ${ }^{[3]}$ Kim et al had a $30.1 \%$ incidence of complications with $18.3 \%$ mechanical and $12.8 \%$ infective. ${ }^{[4]}$ The higher complication rate observed in our study when compared to Kim and Jain et al was due to inclusion of catheter leak as a major complication and non availability of dedicated nurse team for CVC care. In Babu et al study, difficulty during insertion was seen in $7.78 \%$ which is 
comparable to $6.3 \%$ in our study. ${ }^{[2]}$ Similarly, difficulty in the placement of catheters was found in $5 \%$ cases of Certofix and $12.5 \%$ cases of Cavafix by Kumar et al. ${ }^{[5]}$

Persistent withdrawal occlusion was seen in $4.8 \%$ in our study, whereas Babu et al reported $0.93 \%$ and Kumar et al reported a high incidence of $10-25 \%$ with all their patients able to complete treatment without the need for second CVC. ${ }^{[2,5]}$ Accidental dislodgement was seen in $7.9 \%$ (all were of Cavafix) in our study which is less compared to $10.9 \%$ by Babu et al. ${ }^{[2]}$ This can be prevented by suturing. However, Cavafix lacks a suture hub in its design. Catheter leak was seen in $4.8 \%$ of our PICCs and were salvaged by a catheter repair kit.

The CRBSI rate ranged from as low as $7 \%$ in Jain et alto $60 \%$ in Kim et al. ${ }^{[3,4]}$ In our study CRBSI was $19.2 \%$ and blood cultures yielded Staphylococcus aureus as the commonest organism. Babu et al and Nirni et al found Staphylococcus aureus, while Jain et al found Pseudomonas aeruginosa and Kumar et al found Staphylococcus epidermidis to be the most common isolate. ${ }^{[2,6,3,5]}$

Thrombotic complications were seen in $3.2 \%$ of our study which is comparable to various studies. Thrombolytic agents such as urokinase or streptokinase to clear catheter blocks were not used in our patients because of financial reasons. A comparison of complications reported in various studies has been shown in Table 3.

Table 3: Comparison of outcomes among various studies

\begin{tabular}{lllllll}
\hline Study & $\begin{array}{l}\text { Babu } \\
\text { et al }\end{array}$ & $\begin{array}{l}\text { Jain et } \\
\text { al }\end{array}$ & $\begin{array}{l}\text { Kim } \\
\text { et al }\end{array}$ & $\begin{array}{l}\text { Kumar } \\
\text { et al }\end{array}$ & $\begin{array}{l}\text { Nirni } \\
\text { et al }\end{array}$ & $\begin{array}{l}\text { Our } \\
\text { study }\end{array}$ \\
\hline $\begin{array}{l}\text { Sample size } \\
\text { Median } \\
\text { duration } \\
\text { (days) }\end{array}$ & 180 & 213 & 179 & 100 & 50 & 63 \\
$\begin{array}{l}\text { Venous } \\
\text { thrombosis }\end{array}$ & 76 & 89 & 46 & 109 & 84 & 98 \\
$\begin{array}{l}\text { Difficulty in } \\
\text { insertion }\end{array}$ & 12.9 & NA & NA & 7 & NA & 6.3 \\
$\begin{array}{l}\text { Persistent } \\
\text { withdrawl } \\
\text { occlusion }\end{array}$ & 0.93 & NA & NA & 10 & NA & 4.8 \\
\hline $\begin{array}{l}\text { Accidental } \\
\text { dislodgement }\end{array}$ & 10.19 & NA & 4.5 & 10 & NA & 7.9 \\
$\begin{array}{l}\text { CRBSI } \\
\text { Organism }\end{array}$ & 18.8 & 40 & 12.8 & 15 & 26 & 19.2 \\
\hline
\end{tabular}

The most common reason for catheter removal was treatment completion suggesting that CVCs are safe and reliable for long term venous access. The notable limitation in our experience has been the challenge in dedicating a trained nurse and a clinic to the care of venous access devices. Experience in large cancer centers has shown that the longevity, safety, and efficacy of CVCs improve significantly with such a dedicated clinic and trained staff.

\section{CONCLUSION}

Central venous catheters are an accecptable and safe method for administration of chemotherapy and supportive medication for prolonged periods. The incidence of various complications and catheter loss was acceptable. The cost of the device forms a crucial factor in choosing the type of CVC. Its maintenance requires expert care, and training of doctors, nurses, patients and care givers.

\section{ACKNOWLEDGEMENT}

DrJyosthna and Dr Pradeep have drafted the idea and done sample collection and data entry. DrJyosthna under guidance of DrChiltakar, analysed data and reviewed discussion.

\section{REFERENCES}

[1] Schiffer CA, Mangu PB, Wade JC, et al. Central venous catheter care for the patient with cancer. American Society of Clinical Oncology clinical practice guideline. J Clin Oncol. 2013;31:1357-70.

[2] Babu KG, Suresh Babu MC, Lokanatha D, et al. Outcomes, cost comparison, and patient satisfaction during long-term central venous access in cancer patients: Experience from a Tertiary Care Cancer Institute in South India. Indian J Med Paediatr Oncol. 2016;37:232-8.

[3] Jain S, Shukla $S$, Talati $S$, et al. A retrospective study of central venous catheters GCRI experience. Indian J Med Paediatr Oncol. 2013;34:238-41.

[4] Kim HJ, Yun J, Kim HJ, et al. Safety and effectiveness of central venous catheterization in patients with cancer: prospective observational study. $\mathrm{J}$ Korean Med Sci. 2010;25:1748-53.

[5] Kumar AH, Srinivasan NM, Thakkar JM, et al. A prospective observational study of the outcome of central venous catheterization in 100 patients. Anesth Essays Res. 2013;7:71-5.

[6] Nirni S, Shukla S, Shah P, et al. Study of various types of central venous catheters with respect to their complications. Indian J Med Paediatr Oncol. 2002;23:21-4

\section{AUTHORS}

First Author - DrJyosthnaElagandula, Senior Resident, Department of Medical Oncology, SAIMS, jyosthna.elagandula@gmail.com.

Second Author - Dr Pradeep Kumar Reddy K, Senior Resident, Department of Medical Oncology, SAIMS,

kpkreddy.medonco@gmail.com.

Third Author - Dr Prakash G. Chitalkar, Professor and Head of department, Department of Medical Oncology, SAIMS, prakash.chitalkar@gmail.com.

Correspondence Author - DrJyosthnaElagandula, Senior Resident, Department of Medical Oncology, SAIMS, jyosthna.elagandula@gmail.com. 